\title{
The US biological sciences faculty gap in Asian representation
}

\author{
James Meixiong' and Sherita Hill Golden ${ }^{2}$ \\ 'Medical Scientist Training Program, Johns Hopkins University, Baltimore, Maryland, USA. ${ }^{2}$ Vice President and Chief Diversity Officer, Office of Diversity, Inclusion, and Health Equity. Hugh P. McCormick \\ Family Professor of Endocrinology and Metabolism, Department of Medicine, Johns Hopkins University School of Medicine, Baltimore, Maryland, USA.
}

In the past year, the COVID-19 pandemic has inflicted untold human suffering, remade the global economy, and highlighted numerous weaknesses in political, health, and social systems. In the United States, Asian Americans and immigrants have faced increased xenophobia, as evident by exponential increases in reported hate crimes and the horrific massage parlor shootings in Atlanta. This tragic spate of violence has renewed conversation on America's long history of anti-Asian discrimination, from prior racist immigration policy like the Chinese Exclusion Act of 1882, to the more recent model-minority myth of Asian attainment. In order to build a more equitable society, it is important to discuss and acknowledge the impact of this history, including in the biomedical sciences.

\section{Persistence of structural barriers to entry into academic biomedical sciences}

As illustrated by the 2019 National Science Foundation Report on Women, Minorities, and Persons with Disabilities in Science and Engineering, the demographics of US biological sciences trainees and academic faculty do not mirror that of its general population (1). Pernicious structural racism continues to create disparities across and within academic science. Long underrepresented in the biological sciences, Blacks and Hispanics make up an estimated $31.7 \%$ of the general population, but only $14.7 \%$ of research trainees $(-17.0 \%$ difference, indicating a gap in representation), and $5.4 \%$ of biological sciences faculty $(-26.3 \%$ difference) (Table 1). Many institutions have appropriately identified these gaps in representation, and important policies are being enacted to address the societal, cultural, and institutional barriers that prevent marginalized groups from seeking and having access to graduate-level training and becoming faculty $(2,3)$.

\section{Evidence of bias within academic biomedical sciences hierarchy}

Just as academic biomedical science, as a whole, fails to represent the general population, its faculty demographics differ widely from that of a far more diverse trainee population. Blacks, Hispanics, and Asians make up $45.7 \%$ of graduate students (master's and doctoral students) and postdoctoral fellow trainees yet only $28.7 \%$ of faculty (-17.0\% difference) (Table 1). Asians, despite being overrepresented across all levels of the biological sciences when compared with their makeup of the general population (5.9\%), are arguably underrepresented among total faculty $(21.3 \%,+15.4 \%$ difference $)$ relative to their large percentage makeup of trainees $(31.0 \%,+25.1 \%$ difference) (Table 1$)$. This lack of Asian representation among faculty becomes even more stark when the within-faculty hierarchy is examined. The vast majority of faculty positions held by Asians are nontenured positions and not the more desirable tenure-track positions with leadership potential (12.3\%; Table 1). These gaps may be a manifestation of the discriminatory "bamboo ceiling" in academia, whereby Asians occupy correspondingly fewer positions of executive leadership compared with their representation among professional workforces (4-6), and is supported by alternative lines of evidence. For example, in terms of R01 funding, the workhorse grant for independent faculty investigators, Asians are less likely than Whites to receive support

Conflict of interest: The authors have declared that no conflict of interest exists.

despite having more listed publications and citations on their applications $(7,8)$.

Because academic training and promotion often spans many years, current faculty demographics may not reflect more recent efforts to improve diversity. Indeed, the biological sciences workforce has changed significantly in recent years in terms of the ethnicities of students awarded doctorates, postdoctoral fellowship appointments, and faculty positions (1). With this in mind, a useful demographic comparison may be that of past trainee figures to current faculty numbers. As estimated by doctorates awarded and postdoctoral fellow appointments, nonHispanic Whites made up $64.8 \%$ of biological science trainees in 2001 (9). Comparing this figure to more recent 2017 faculty representation yields a $+6.1 \%$ difference. In a similar analysis between percentage representation of 2001 trainees versus 2017 faculty, Asians had a $-7.2 \%$ difference, indicating that the current gap in Asian representation between trainees and faculty is unlikely to be explained by recent changes in trainee demographics.

These discrepancies in Asian representation do not appear to be a result of personal preference. Compared with White colleagues, Asian doctoral recipients pursued postdoctoral fellowships at similar and oftentimes higher rates than their peers $(1,9,10)$ and were similarly interested in obtaining US faculty positions (11). It bears mentioning that a disproportionate percentage of Asian trainees in the United States are temporary visa holders who face higher political and legal barriers to employment and obtaining research funding. It is possible that these trainees, upon completion of their studies, might be motivated to return to their home countries and are not applying to US faculty positions. Although the demographic data presented do not address this possibility, it seems unlikely given that 


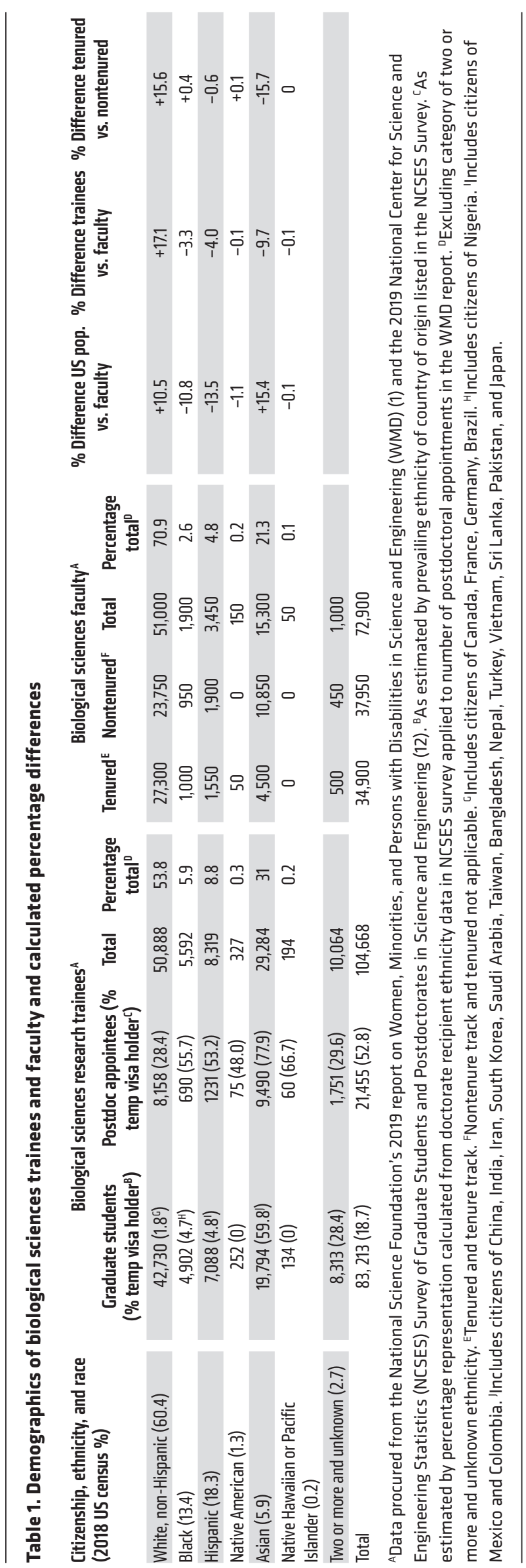

noncitizen postdocs report more interest in pursuing academic research positions (10), the higher relative percentage representation of Asians in nontenured faculty positions, indicating a desire to stay in the country (Table 1), and the fact that the gap in Asian faculty representation has persisted for decades despite large increases in the number and proportion of nonresident postdoctoral and doctoral trainees (1). A national survey of the career plans of postdoctoral fellows with temporary visas as well as knowledge of the current immigration status at the time of faculty hiring is required to fully understand the goals of these trainees and potential barriers to pursuing tenure-track roles.

\section{Our perspective}

Asians have long been considered to be an overrepresented minority in the biological sciences. This conclusion is based on data comparing racial/ethnic representation among biological sciences graduate-level trainees and faculty to that of the general population. However, when academic hierarchy is considered, Asian representative status becomes complicated. Based on their relative proportion of graduate students, postdoctoral fellows, and nontenured faculty, Asians are arguably underrepresented at the tenured faculty level. Such gaps in representation should be discussed and better addressed by policy.

Science, as an equitable marketplace of ideas and impartial data, is most healthy when principles of fairness, diversity, and meritocracy are enshrined and protected. In order to build this idealized forum, stakeholders in the US biological sciences should strive to address unequal workforce representation, wherever they may be and to whomever they may apply. This includes the structural inequality that impacts access to graduate-level training of Black, Hispanic, Indigenous, and others underrepresented in medicine and science as well as the challenges that all minoritized scientists face within academia: inadequate institutional support, lack of mentorship, and biased hiring, funding, and promotion processes. Creating an equitable workforce - where no person, at any stage of their training and career, is disadvantaged by their race or ethnic group - is critical to developing and advancing scientific innovations. Creating academic 
settings with diverse medical and graduate students, postdoctoral fellows, and faculty, equally represented at all levels, will better position us to address and solve our future biomedical challenges.

\section{Acknowledgments}

James Meixiong received funding from the Hopkins MSTP grant T32 GM73009. Thank you to Sze Yan Janelle Ho, Lin Mei, Wen-Cheng Xiong, Jawara Allen, Chirag Vasavda, Mark Sabbagh, and Andrea Cox for critical comments. Thank you also to the Johns Hopkins MSTP program administrators Sharon Welling, Martha Buntin, and Bernadine Harper.

Address correspondence to: James Meixiong, 1830 E. Monument Street, Suite 2-300, Baltimore, Maryland 21205, USA. Phone: 410.614.6249; Email: jmeixio1@ jhmi.edu. Or to: Sherita Hill Golden, 1620
McElderry Street, Reed Hall, Room 420, Baltimore, Maryland 21205, USA. Phone: 443.287.4827; Email: sahill@jhmi.edu.

1. National Science Foundation. Women, Minorities, and, Persons with Disabilities in Science and Engineering Report 2019. https://ncses.nsf. gov/pubs/nsf19304/. Updated March 8, 2019. Accessed May 24, 2021.

2. Freeman BK, et al. Understanding the leaky pipeline: perceived barriers to pursuing a career in medicine or dentistry among underrepresented-in-medicine undergraduate students. Acad Med. 2016;91(7):987-993.

3. Allen-Ramdial SA, Campbell AG. Reimagining the pipeline: advancing STEM diversity, persistence, and success. Bioscience. 2014;64(7):612-618.

4. Gasman M, et al. Diversity and senior leadership at elite institutions of higher education. J Divers High Educ. 2015;8(1):1-14.

5. Lu JG, et al. Why East Asians but not South Asians are underrepresented in leadership positions in the United States. Proc Natl Acad Sci US A. 2020;117(9):4590-600.

6. Hyun J. Breaking the Bamboo Ceiling: Career Strat- egies for Asians. Harper Collins; 2005.

7. Ginther DK, et al. Race, ethnicity, and NIH research awards. Science. 2011;333(6045):1015-1019.

8. Ginther DK, et al. Publications as predictors of racial and ethnic differences in NIH research awards. PLoS One. 2018;13(11):e0205929.

9. National Science Foundation. Women, Minorities, and, Persons with Disabilities in Science and Engineering Report 2004. https://www. nsf.gov/statistics/archive-goodbye.cfm?p=/ statistics/wmpd/archives/wmpd_2004.zip. Updated August 26, 2019. Accessed May 24, 2021.

10. McConnell SC, et al. United States National Postdoc Survey results and the interaction of gender, career choice and mentor impact. Elife. 2018;7:e40189.

11. Gibbs KD Jr, et al. Biomedical science Ph.D. career interest patterns by race/ethnicity and gender. PLoS One. 2014;9(12):e114736.

12. National Science Foundation. Statistics Survey of Graduate Students and Postdoctorates in Science and Engineering: Fall 2019. https://ncses. nsf.gov/pubs/nsf21318. Updated March 1, 2021. Updated May 24, 2021. 